\title{
IMPLEMENTATION OF AUTHENTICITY AND NOMINAL MONEY DETECTION SYSTEMS FOR MICROCONTROLLER-BASED BLINDNESS
}

\author{
Aprizal \\ Sistem Informasi, STMIK Dipanegara Makassar, Indonesia \\ aprizal@dipanegara.ac.id
}

\begin{abstract}
Money is a tool used to using in sale and purchase transactions. It's has been using by people everywhere. Money is a staple for everyone, even for disabilities such us blind people. The limitation of the blind people in terms of seeing is a problem in communication so they rely solely on the sense of touching and listening. This limitation can make them confuse to identified money, miscalculation, or even deceived when selling. Referring to the above, it is necessary a tool that can facilitate the blind to identify the authenticity and nominal value of money. The purpose of this study is to design a tool that can be used to detect the authenticity and nominal value of banknotes. This tool uses TCS3200-DB color sensor to detect the color of banknotes, and ultraviolet sensors to detect the authenticity of money. Then by the microcontroller converted into RGB data and issued in the form of sound. Type of research used is the type of qualitative research with experimental methods, and using Black Box testing techniques. The result of this study is the system can recognize the authenticity and nominal money. So that makes it easier for users, especially blind people in buying and selling transactions in order not to change money.
\end{abstract}

Keywords: Blind; Color Sensor; Paper Money; Sound; Ultraviolet Sensor.

\section{INTRODUCTION}

Rupiah banknotes are money in the form of sheets made of paper or other materials (which resemble paper) issued by the Indonesian government, and legally used as a means of payment in the territory of the Republic of Indonesia. The authenticity of Rupiah can be identified through the characteristics found in both the material used to make money (paper, plastic, or metal), the design and color of each of the denominations and the printing techniques. Some of the characteristics contained in the Rupiah, in addition to functioning as a feature to distinguish between one fraction and another, can serve as a safeguard against the threat of money fraud.

The safety device consists of invisible safety equipment, tangible, and new security is seen by using aids in the form of ultra violet rays, infrared rays, magnifying glass, and certain plastic tools to see scramble images. In plain view, we can distinguish original banknotes from counterfeit banknotes by being seen, touched and exposed. Original banknotes have security threads, watermarks, glossy prints and embossed prints that feel rough when touched [1].

But this is not the case with blind people who have physical limitations in distinguishing between original and fake banknotes. So far, blind people use conventional methods such as making nominal banknotes or making a fold on money to distinguish the nominal money. However, it still has some weaknesses, namely in terms of blind memory, physical condition of money and lack of honesty determinants that when dealing in the sale and purchase of goods and services, the person invited to transact gives money in accordance with the nominal value and directs the tuna blind to arranging the money correctly.

According to the survey of Sight and Hearing in 1993-1996, the highest number of blindness in Indonesia was 1.5\% in Asia, compared to Bangladesh $1 \%$, India $0.7 \%$, and Thailand $0.3 \%$. This means that if there are 12 world population blind in every 1 hour, four of them come from Southeast Asia and one person is confirmed from Indonesia [1].

Referring to the above problems, it is necessary to help people with visual impairments who can identify the authenticity and nominal value of banknotes by detecting the color of the banknote. Thus, it is hoped that it can facilitate persons with visual impairments in the activities of buying and selling goods and services.

In accordance with its development, lately Bank Indonesia has printed money with certain printing techniques that are more difficult to replicate. Because in the print, BI implements additional features as characteristics of authenticity of money. So that people can recognize the money is genuine or fake using a tool called ultra violet lights, so as to minimize the crime of circulating counterfeit money. To be able to know the nominal money, a color sensor can be used. A color sensor is a device that detects objects directly and then processes them in the form of analog/digital signals [1].

This paper will use one of the sensor implementations to detect the nominal value of rupiah banknotes. This implementation uses a color sensor, the data obtained from the color recognition of banknotes by the color sensor then enters the microcontroller. The data available on the microcontroller is still in the form of analog data. For this reason, a converter component is needed to convert analog data into digital data. After processing the data, finally the sound output is obtained which tells the nominal value of the banknote to be known.

Solutions that are expected to minimize fraud and fraud against people with disabilities are none other than the use of technological developments. Therefore, this technological development is the background of the problem of this study, which is the expected application of this technology to be able to help people with disabilities in this case blind people.

\section{Application}

The application comes from the word application which means application, application, usage. In terms of application is a ready-made program that is made to carry out a function for 
users or other applications and can be used by the intended target. Understanding the application according to the large Indonesian dictionary [2] is the application of a system design to process data that uses rules or provisions of certain programming languages.

\section{Money}

Money is something that is generally accepted in payments for the purchase of goods and services and for payment of debt. According to [3], money can function as a medium of exchange, a unit of calculation, a pen tool.

Nominal money

The data obtained will be used as a reference for variable values that are used as limits to be able to distinguish each banknote. The variables used are basic colors consisting of red, green and blue which are represented by variables $R, G$ and $B$ and the size of money defined by edge variables. The following will show the limits on each money used [4].

\section{Ultraviolet sensor}

This ultraviolet light sensor is useful for detecting ultraviolet light intensity with analog output. This sensor can detect ultraviolet light with a wavelength from $200 \mathrm{~nm}$ to 370 nm with a high sensitivity level. The power supply can use a voltage range of $3 \mathrm{~V}$ to $5 \mathrm{Volt} \mathrm{DC}$ with a current consumption below $0.1 \mathrm{~mA}$ (typically only $60 \mu \mathrm{A}$ ). This electronic module can be operated in the temperature range of $-20^{\circ} \mathrm{C}$ to $+85^{\circ}$ C.The output of this module is in the form of a voltage between 0 to 1 Volt DC, can be connected directly to the analog pin (ADC / Analog-to-Digital Converter) on the microcontroller [5].

\section{Microcontroller}

Microcontroller is a microprocessor that is devoted to instrumentation and control. Microcontroller is a digital electronic device that has input and output as well as control with programs that can be written and deleted in a special way. Each microcontroller has a different architecture depending on the design. Even so, each microcontroller architecture basically has uniformity in the principal and how it works [6].

\section{Arduino Mega}

Arduino Mega2560 is an ATmega2560 based microcontroller board. Arduino Mega2560 has 54 digital input / output pins, where 15 pins can be used as PWM output, 16 pins as analog input, and 4 pins as UART (serial port hardware), $16 \mathrm{MHz}$ crystal oscillator, USB connection, power jack, ICSP header, and reset button. This is all that is needed to support the microcontroller. Simply connect it to a computer via a USB cable or power connected to the AC-DC adapter or battery to start activating it. Arduino Mega2560 is compatible with most shields designed for Arduino Duemilanove or Arduino Diecimila. Arduino Mega2560 is the latest version that replaces the Arduino Mega version [7].

\section{Sensor}

The sensor is a tool for detecting / measuring something, which is used to change mechanical, magnetic, heat, light and chemical variations into electrical voltages and currents. In a controller and robotics system environment, sensors provide similarities that resemble the eyes, hearing, nose, tongue which will then be processed by the controller as the brain [3].

\section{Color Sensor}

Color sensors can be interpreted as a particular spectrum contained in perfect / white light. Color is divided into 2, namely primary color and secondary color. The primary color is the basic colors, while the secondary color is the color produced from a mixture of two primary colors in a color space [5].

\section{Liquid Crystal Display (LCD)}

A digital display technology that produces images on a flat surface by shining a liquid crystal and a colored filter, which has a polar molecular structure, sandwiched between two transparent electrodes. When an electric field is given, the molecule adjusts its position to the field, forming a crystalline arrangement that polarizes the light passing through it.

Although called a point of light, this liquid crystal does not emit its own light [8]. The light source in an LCD device is a white fluorescent lamp on the back of the liquid crystal arrangement. This point of light that is tens of thousands or even millions is what forms the appearance of the image. The liquid crystal poles that are passed through the electric current will change due to the influence of the magnetic field polarization that arises and therefore will only allow some colors to continue while the other colors filter.

\section{METHOD}

Data collection is one of the important things to do in obtaining the desired data. With the data taken, it is very helpful in producing the desired information. In this proposal, the authors collect data through: (1) Primary Data. Primary data is data obtained or collected from the company. The primary data collection uses a field study method, namely: Interview, which is data collection conducted by direct interviews with staff of the Office of the Indonesian Blind Foundation. Observation, which is a direct observation of the location of the research, namely the Office of the Indonesian Blind Foundation.

Secondary data, namely the data obtained or collected from existing sources, both derived from articles and various other sources that relate to the problems that the author carefully examined. Secondary data collection uses documentation method, which is collecting data obtained from article sources obtained from the internet and studying or reading the opinions of experts related to the problem under study to obtain a theoretical basis that can lead to research and from previous records.

The tools used to design and create systems shown in Fig. 1. The hardware which use to develop and collect data on this application are (1) Acer Aspire V5-132 Laptop with specifications of Intel Dual-Core Processor (2 Core), 500 GB Hard Drive, 4 GB Memory, (2) Epson L360 series Printer, scan and copy, (3) Sensor (Color, UV), (4) LCD. The software what use are: (1) 32 bit Windows 7 Operating System, (2) Arduino UNO Software (Atmega328). Materials used in this study are (1) banknotes, (2) blind people and authors' biographies. 


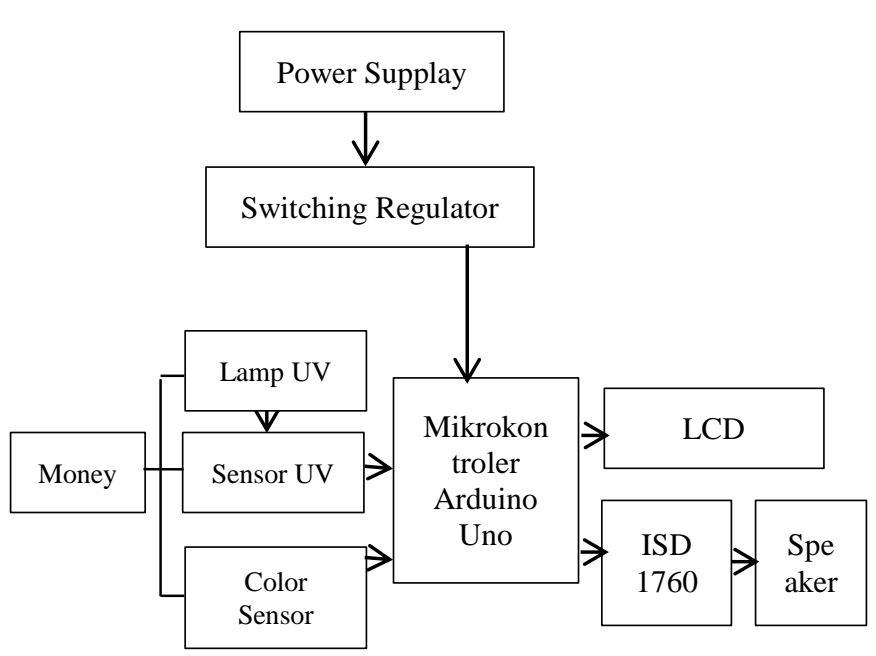

Fig. 1. Block Diagram

\section{RESULT AND DISCUSSION}

\section{A. Switching Regulator Series}

Arduino Uno Microcontroller, Color Sensor and ISD1760 can work if given a $5 \mathrm{~V}$ voltage supply. In this design, a power of $5 \mathrm{~V}$ is obtained from the MC34063 Switching Regulator circuit. The switching regulator circuit is as in figure 2 as follows.

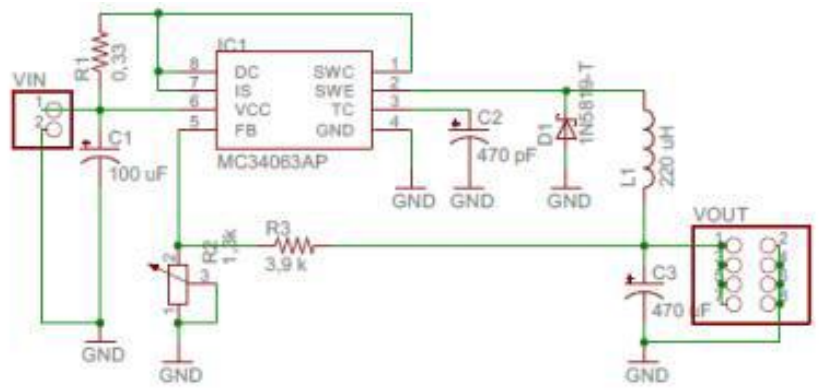

Fig. 2. Switching Regulator Series

\section{B. Color Sensor Series}

The color sensor functions to read the color of objects that have been detected. The color sensor used in this tool is TCS3200. IC TCS3200 is an IC that converts the color of light to frequency, each color can be arranged from the base color. For light, the basic colors of the arrangement are Red, Green and blue, or better known as RGB (Red-Green-Blue). The color sensor circuit is as shown in Figure 3 as follows.
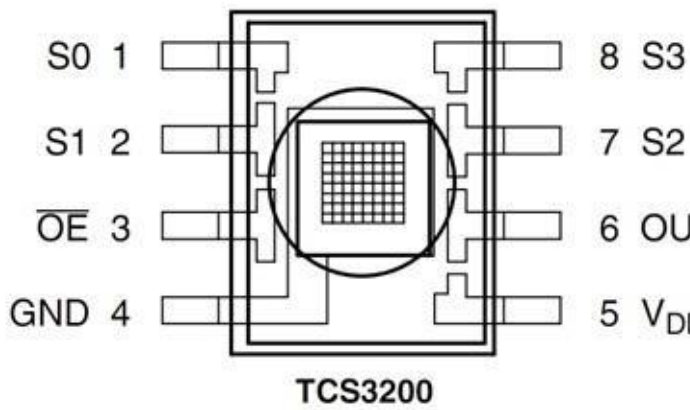

7 S2

6 OUT

$5 V_{D D}$
The microcontroller functions as the main controller in the entire system such as retrieving and processing data output from the color sensor and ultraviolet sensor which is then released through the LCD and ISD1760 sound memory. This board has a lot of I / O pins, 54 digital I / O pins (15 of which are PWM), 16 analog input pins, 4 UART pins (hardware serial port). The Arduino Uno circuit is as shown in Figure 4 as follows.

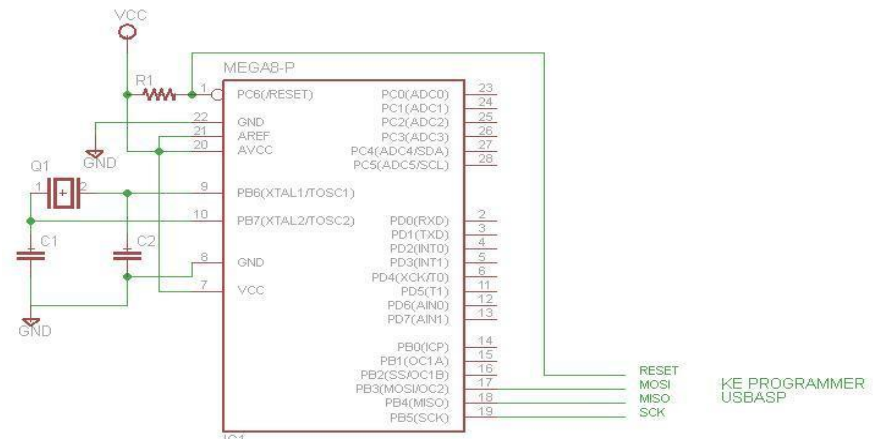

Fig. 4. Arduino Uno series

The using ISD1760 voice IC is used to play back the recorded voice, namely the sound of authenticity and the nominal value of money. The thing to note in the recording process is the distance between one voice and another voice must have a different address and the sound at the first address does not affect the sound at another address. The ASD1760 IC circuit is as in Figure 5 as follows.

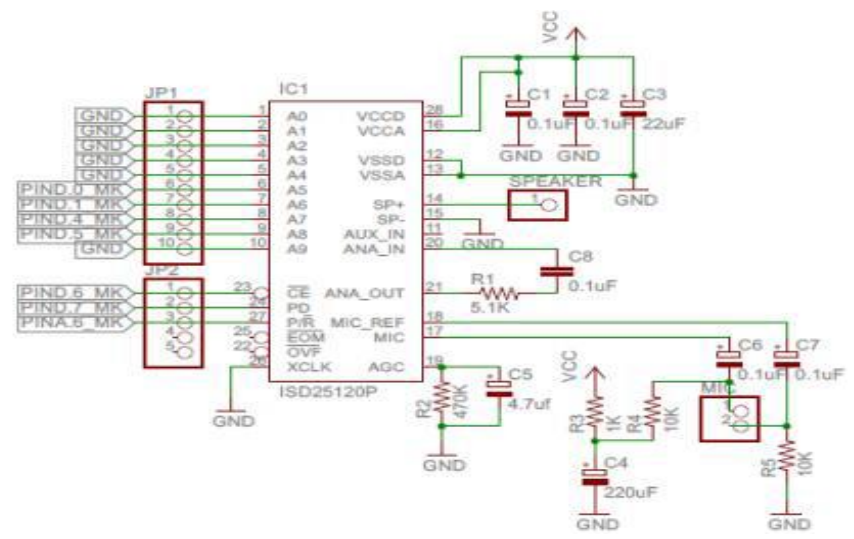

Fig. 5. ISD1760 IC circuit

The whole series is as shown in Figure 6 as follows.

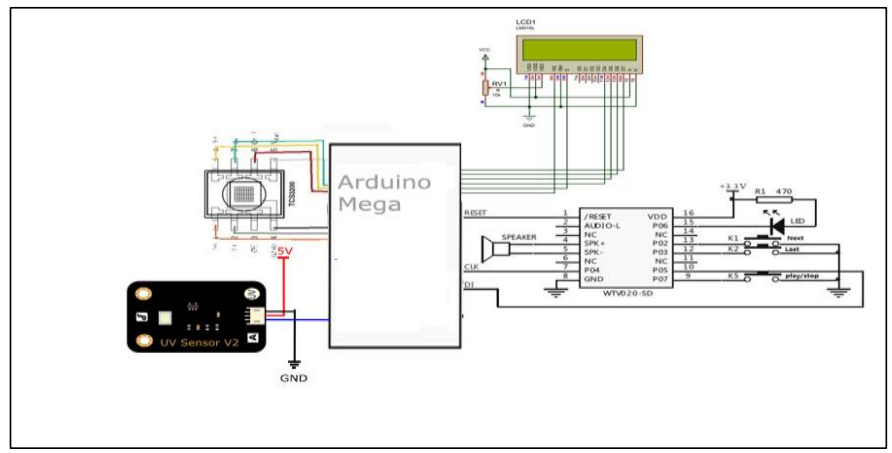

Fig. 6. Overall Series

Fig. 3. Color Sensor Series 


\section{CONCLUSION}

Based on the results of research that has been conducted, conclusions might be draw (1) currency detection system can function at a nominal value of IDR 5,000 up to IDR 100,000 by displaying the nominal money on the screen along with the sound produced in accordance with the nominal value of money. (2) From the results of the Black Box test, it is found that the computerized system developed or proposed avoids programming logic errors to process the nominal value of money on a nominal money detector. (3) The effect of good and bad gradation physical condition of banknotes greatly affect the frequency reading by color sensors. The better the physical condition of the money, the more physical color of money will appear. Whereas for money with gradations and poor physical conditions will lead to an RGB color overlap with each other so that the results of reading the data have errors.

\section{ACKNOWLEDGMENT}

Author say Thanks a lot of to Allah SWT who has giving me his mercies to finish this research. Also, I thank to everyone who helps and contributes in this research especially my family and friend. May this paper give advantage to all of us.

\section{REFERENCES}

[1] D. A. Porbadi, "Banknote Nominal Detection Tool for People with Blindness," Journal of Electrical Engineering, vol. 1, no. 1, pp. 1-6, 2014.

[2] Kemendikbud, Indonesian Dictionary of Large Dictionary (KBBI), "Application Application", Jakarta, 1998.

[3] F. D. Petruzella, Electronics Industry, Yogyakarta: Andi, 2001.

[4] D. Wicaksono, "Identification of Nominal Value and Authenticity of Rupiah Banknotes Using Backpropopagation Neural Networks," Journal of Electrical Engineering, vol. 1, no. 1, pp. 1-11, 2008.

[5] S. Sabrie, Sensors and Control Systems in Manufacturing, United States: McGraw-Hill Companies, 2010.

[6] S. Setiawan, Easy and Fun Microcontroller Learning, Yogyakarta: Grahallmu, 2006.

[7] F. Djuandi, Microcontroller, Yogyakarta: Andi, 2011.

[8] A. Munandar, 16x2 (LCD) Liquid Crystal Display, 2012. 